\title{
EVALUATION OF STORAGE ROOT YIELD, DRY MATTER AND STARCH CONTENT IN F 1 PROGENIES OF SWEETPOTATO (Ipomoea batatas (L.) Lam) OBTAINED FROM CONTROLLED CROSS SYSTEM
}

\author{
Ulasi Joseph Ifeanyi ${ }^{1 *}$, Okim Rinene Samuel ${ }^{2}$ and Keyagha Eberechi Rosemary ${ }^{3}$ \\ ${ }^{1}$ Department of Crop Science, Faculty of Agriculture, University of Uyo, \\ ${ }^{1}$ P.M.B 1017, Uyo, Akwa, Ibom State. \\ ${ }^{2}$ Department of Agronomy, College of Crop and Soil Sciences, \\ ${ }^{2}$ Michael Okpara University of Agriculture, Umudike, P.M.B 7267, Umuahia, Abia State, Nigeria. \\ ${ }^{3}$ Department of Crop Science and Technology, Federal University of Technology, \\ ${ }^{3}$ P.M.B. 1526, Owerri, Imo State \\ https://doi.org/10.35410/IJAEB.2021.5682
}

\begin{abstract}
High yield and dry matter are important characteristics of sweetpotato varieties in addition to starch content which has industrial applications. The objective of this study was to evaluate the performance of progenies sweetpotato obtained from controlled cross system for higher root yield, dry matter and starch content. Field experiment was conducted at the National Root Crops Research Institute, Umudike, Southeast Nigeria during the 2015 and 2016 cropping seasons to evaluate diversity across progenies of three (3) sweetpotato families; SautiX442162 (6), LigriXFaara (17), SautiXBohye (17), including two check varieties (Umuspo3 and TIS 87/0087). This experiment was laid out in a randomized complete block design with three replicates. The variables observed included: number of root per plot, the weight of root per plot, dry matter content, root yield and starch content. The analysis of variance showed a significant difference among the tested genotypes in most of traits observed. Root yield ranged from 2.2- 19.33t/ha and starch content ranged from $80.11 \mathrm{mg} 100 \mathrm{~g}-1$ to $20.76 \mathrm{mg} 100^{-1}$. SautiX442162/1 had the highest starch content, $80.11 \mathrm{mg} 100 \mathrm{~g}^{-1}$ while SautiXBohye/9 had the lowest starch content, $20.76 \mathrm{mg} 100^{-1}$. Five promising genotypes; LigriXFaara/2 (14.67t/ha), LigriXFaara/3 (16.02t/ha), SautiXBohye/1 (15.03t/ha), SautiXBohye/2 (19.33t/ha), SautiXBohye/3 (16.00t/ha) recorded high yield above the world's estimated annual average yield of $13.7 \mathrm{t} / \mathrm{ha}$. Six promising genotypes recorded starch content above 50mg100-1; SautiX442162/1 (80.11mg100-1), SautiX442162/3 (77.51 mg100-1), SautiX442162/2 (66.14mg100-1), SautiX442162/6 (57.36

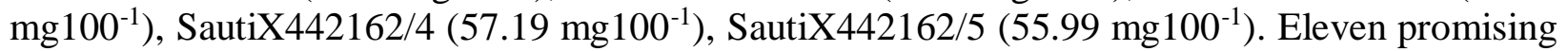
genotypes that recorded high yield and starch could be subjected to multi-location trail and incorporated into further breeding program.
\end{abstract}

Keywords: Dry matter, Ipomoea batatas, Progenies, Storage root, Starch, Sweetpotato.

\section{INTRODUCTION}

Sweetpotato (Ipomoea batatas (L.) Lam) is a dicotyledonous tuber from the Convolvulaceae family and it is an important stable crop that is consumed in many developing countries in the tropics (Thottappilly and Loebenstein, 2009). Sweetpotato is a low-cost crop that is commonly utilized as a food, feed and a good source of starch (Odebode, 2004). Across the globe, the 
Vol. 06, No. 06; 2021

ISSN: $2456-8643$

annual sweetpotato production is estimated at $110.7 \mathrm{t}$ over an area of 8.2 million ha with a productivity of 13.5t/ha. China is the world's largest producer of around 79 ton around 3.5 million ha (FAO, 2013). The crop is predominately grown in developing nations of the world where over $95 \%$ of the global production is recorded (Loebenstein, 2009). Africa accounts for about $15 \%$ of the sweetpotato production across the globe (Loebenstein, 2009). Worldwide, the average annual production of sweetpotato is around 131 million tonnes, grown on an estimated 9 million hectares with an estimated yield of 13.7 t/ha (FAOSTAT, 2009). In Nigeria, annual yields of common local varieties of sweetpotato in the south-eastern zone is approximated while in the northern part of the country, it is 3.5t/ha, except for Plateau and Bauchi States with an annual average yield of 7 to 8 t/ha (Tewe, et al., 2003). Fresh storage root of sweetpotato has low glycaemic index, considering the slow rate of digestion of its complex carbohydrate and its lower rate of absorption of sugars into the blood stream. It is therefore, a suitable source of food for the diabetics (Willcox et al., 2009). Sweetpotato has numerous industrial uses (Lin et al., 2007). It is a common source of industrial raw materials such as starch and alcohol, yielding $30-50 \%$ higher starch compared to rice, corn and wheat sources under same environmental conditions (Rahman et al., 2003). 70 percent of the dry weight of sweetpotato is constituted by the starch content and high dry matter content serves as a significant characteristic of a good sweetpotato variety (Mwanga et al., 2007). Starch contributes to the textural properties of foods products and it is widely used for food and industrial applications as thickener, colloidal stabilizer, and gelling, bulking and water retention agent (Singh et al., 2008).

Evaluation of newly developed progeny in yield trial could reveal some promising genotypes with high root yields and other desirable agronomic traits. The aim of this study was to evaluate forty sweetpotato progenies obtained from controlled cross system for storage root yield, dry matter and starch content.

\section{MATERIALS AND METHOD}

Study Site: The experiment was carried out during the 2015 and 2016 planting seasons at the National Root Crops Research Institute, Umudike, Southeast Nigeria. Umudike is located at latitude $05^{\circ} 29^{\prime} \mathrm{N}$, longitude $07^{\circ} 33^{\prime} \mathrm{E}$, altitude $122 \mathrm{~m}$ above sea level. Umudike is located in the humid tropics and has a total rainfall of around 2,177 $\mathrm{mm}$ per year, an average annual temperature of around $26{ }^{\circ} \mathrm{C}$ and its soil is classified as sandy-loamy Utisol (NRCRI, 2012).

2.1 Nursery Management: The nursery soil consisted of a mixture of topsoil, organic material and river sand in a ratio of 3: 2: 1 . The nursery was prepared in the greenhouse of the National Root Crops Research Institute, Umudike and Southeast, Nigeria using polyethylene bags containing $1 \mathrm{~kg}$ of soil. After the seeds were soaked in cold water for about twenty-four hours to break the dormancy, some of the seeds that germinated and were carefully isolated from the container with cold water and sown separately in the well-watered soil in polyethylene bags.

2.2 Agronomic practices: The land for the trial site was cleared, ploughed, harrowed and skinned. The prepared land was demarcated in plots of $1.5 \mathrm{~m} 2(1 \mathrm{mx} 1.5 \mathrm{~m})$. The field was laid out in an extended three replicate design and two control varieties were planted at intervals. The planting distance was $1 \mathrm{mx} 0.3 \mathrm{~m}$. This resulted in five stands of sweetpotato per parcel, equivalent to 33,333 stands per hectare. Therefore, the land area for this study was $240 \mathrm{~m}^{2}$. Planting was done on July 21, 2015 and April 18, 2016 with five vines on each plot. The crops were rainfed. 
Weeding was done 6 and 12 weeks after planting (WAP). Compound fertilizer (NPK 15:15:15) was applied at a rate of $400 \mathrm{~kg} / \mathrm{ha} 4 \mathrm{WAP}$ with side placement. Data were collected at $16 \mathrm{WAP}$ (Ezulike et al., 2001) on the number of roots per plot, marketable (less than 100g) and unmarketable roots (greater than $100 \mathrm{~g}$ ) (Levett, 1993).

Table 1: Progenies of Sweetpotato and their sources.

\begin{tabular}{|cll|}
\hline No. & Genotypes & \\
\hline 1. & LigriXFaara/1 & CIP, Kumasa, Ghana \\
2. & LigriXFaara/2 & CIP, Kumasa, Ghana \\
3. & LigriXFaara/3 & CIP, Kumasa, Ghana \\
4. & LigriXFaara/4 & CIP, Kumasa, Ghana \\
5. & LigriXFaara/5 & CIP, Kumasa, Ghana \\
6. & LigriXFaara/6 & CIP, Kumasa, Ghana \\
7. & LigriXFaara/7 & CIP, Kumasa, Ghana \\
8. & LigriXFaara/8 & CIP, Kumasa, Ghana \\
9. & LigriXFaara/9 & CIP, Kumasa, Ghana \\
10. & LigriXFaara/10 & CIP, Kumasa, Ghana \\
11. & LigriXFaara/11 & CIP, Kumasa, Ghana \\
12. & LigriXFaara/12 & CIP, Kumasa, Ghana \\
13. & LigriXFaara/13 & CIP, Kumasa, Ghana \\
14. & LigriXFaara/14 & CIP, Kumasa, Ghana \\
15. & LigriXFaara/15 & CIP, Kumasa, Ghana \\
16. & LigriXFaara/16 & CIP, Kumasa, Ghana \\
17. & LigriXFaara/17 & CIP, Kumasa, Ghana \\
18. & SautiXBohye/1 & CIP, Kumasa, Ghana \\
19. & SautiXBohye/2 & CIP, Kumasa, Ghana \\
20. & SautiXBohye/3 & CIP, Kumasa, Ghana \\
21. & SautiXBohye/4 & CIP, Kumasa, Ghana \\
\hline No. & Genotypes & \\
\hline 22. & SautiXBohye/5 & CIP, Kumasa, Ghana \\
23. & SautiXBohye/6 & CIP, Kumasa, Ghana \\
24. & SautiXBohye/7 & CIP, Kumasa, Ghana \\
25. & SautiXBohye/8 & CIP, Kumasa, Ghana \\
26. & SautiXBohye/9 & CIP, Kumasa, Ghana \\
27. & SautiXBohye/10 & CIP, Kumasa, Ghana \\
28. & SautiXBohye/11 & CIP, Kumasa, Ghana \\
29. & SautiXBohye/12 & CIP, Kumasa, Ghana \\
30. & SautiXBohye/13 & CIP, Kumasa, Ghana \\
31. & SautiXBohye/14 & CIP, Kumasa, Ghana \\
32. & SautiXBohye/15 & CIP, Kumasa, Ghana \\
33. & SautiXBohye/16 & CIP, Kumasa, Ghana \\
34. & SautiXBohye/17 & CIP, Kumasa, Ghana \\
\hline
\end{tabular}


Vol. 06, No. 06; 2021

ISSN: $2456-8643$

$\begin{array}{lll}\text { 35. } & \text { SautiX442162/1 } & \text { CIP, Kumasa, Ghana } \\ \text { 36. } & \text { SautiX442162/2 } & \text { CIP, Kumasa, Ghana } \\ \text { 37. } & \text { SautiX442162/3 } & \text { CIP, Kumasa, Ghana } \\ \text { 38. } & \text { SautiX442162/4 } & \text { CIP, Kumasa, Ghana } \\ \text { 39. } & \text { SautiX442162/5 } & \text { CIP, Kumasa, Ghana } \\ \text { 40. } & \text { SautiX442162/6 } & \text { CIP, Kumasa, Ghana } \\ \text { 41. } & \text { Umuspo 3 } & \text { Check Variety, Nigeria } \\ \text { 42. } & \text { TIS 87/0087 } & \text { Check Variety, Nigeria }\end{array}$

\subsection{Dry Matter Determination}

Dry matter content was determined within twenty four (24) hour after harvest, two medium sized fresh storage roots per genotypes was sliced into small pieces and $100 \mathrm{~g}$ of each tuber samples was dried in hot air oven at $80^{\circ} \mathrm{C}$ for 24 hours until a constant mass was attained. Dry matter content was determined by weighing the initial and final weight, and calculating the percentage of dried weight. The same procedures were followed for all the replications.

Dry matter $(\%)=$ Dry weight of the tuber/ Fresh weight of the tuber $\mathrm{x} 100$

\subsection{Determination of Starch Content}

Starch content was determined based on dry matter content of storage roots. Using a dry weight conversion method, dry matter was measured by the percentage of dry weight to the fresh weight of the storage roots. The conversion formula of the starch content in sweetpotato described by Wang, et al. (1989) was followed, i.e., $\mathrm{y}=0.86945 \mathrm{x}-6.34587$, in which $\mathrm{y}$ is the starch content and $\mathrm{x}$ is the dry matter content.

\section{Statistical Analysis}

Harvest data were subjected to Analysis of variance (ANOVA) and mean separation was carried out using the Least Significant Difference (LSD) test at 5\% level of significance. Data for dry matter and starch content were subjected to an Analysis of Variance (ANOVA). Pearson's correlation analysis was done to show association among yield and yield related components of sweetpotato genotypes. Principal component analysis was done for the yield related traits.

\section{RESULTS}

The results presented in Table 2 showed that in 2015 cropping season, the analysis of variance revealed there were significant $(\mathrm{P} \leq 0.05)$ differences among genotypes for unmarketable root number, marketable root number, marketable root weight, yield, dry matter and starch contents but there was no significant difference among the genotypes for unmarketable root weight (Table 2). In 2016 cropping season, analysis of variance showed that there were significant $(\mathrm{P} \leq 0.05)$ differences among genotypes for unmarketable root number, marketable root number, unmarketable root weight yield, dry matter and starch contents but there was no significant difference among the genotypes for marketable root weight (Table 2). In 2015 cropping season, SautiXBohye/2 produced the highest fresh storage root yield in 2015 cropping season (19.33t//ha). The fresh storage root yield of both check varieties Umuspo 3 and TIS 87/0087 
Vol. 06, No. 06; 2021

ISSN: $2456-8643$

were 8.66t/ha and 7.86t/ha, respectively (Table 2). In 2016 cropping season, LigriXFaara/4 recorded the highest mean of marketable root weight $(1.25 \mathrm{~kg} / \mathrm{ha})$ and highest fresh storage root yield (9.00t//ha.) The fresh storage root yield of both check varieties Umuspo 3 and TIS 87/0087 were $8.06 \mathrm{t} / \mathrm{ha}$ and $8.33 \mathrm{t} / \mathrm{ha}$, respectively.

SautiXBohye/1, SautiXBohye/2, SautiXBohye/4, SautiXBohye/6, LigriXFaara/1, LigriXFaara/2, LigriXFaara/3 had high yield and dry matter content. Table 2 showed that in 2015 cropping season, thirteen genotypes produced higher fresh storage root yield than the national check (TIS 87/0087) while in 2016 cropping season, only LigriXFaara/4 produced higher fresh storage root yield than the national check.

The result presented in Table 2 showed that dry matter and starch contents differ significantly

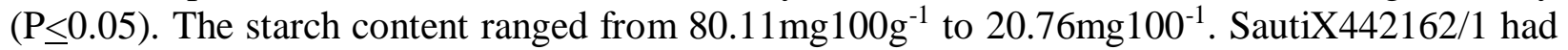
the highest starch content, $80.11 \mathrm{mg} 100 \mathrm{~g}^{-1}$ while SautiXBohye/9 had the lowest starch content, $20.76 \mathrm{mg} 100^{-1}$. The mean of the genotypes for dry matter ranged from $51.50 \%$ to $19.45 \%$. LigriXFaara/8 had the highest dry matter (51.50\%) while SautiX442162/1 had the lowest dry matter $(19.45 \%)$. Among the forty genotypes evaluated, thirty five (35) had dry matter content above 40\%. Six genotypes recorded starch content above 50mg100-1; SautiX442162/1 $\left(80.11 \mathrm{mg}^{100^{-1}}\right), \quad$ SautiX442162/3 $\quad\left(77.51 \mathrm{mg}^{\left.100^{-1}\right),} \quad\right.$ SautiX442162/2 $\quad\left(66.14 \mathrm{mg} 100^{-1}\right)$, SautiX442162/6 (57.36 mg100-1), SautiX442162/4 (57.19 mg100-1), SautiX442162/5 (55.99 $\left.\operatorname{mg} 100^{-1}\right)$.

Table 2: Means of 40 genotypes for total storage root yield for 2015 and 2016 planting seasons

\begin{tabular}{|lcccccccccccc|}
\hline Genotypes & MRN & URN & MRW & URW & Yield & MRN & URN & MRW & URW & Yield & Dry & Starch \\
& $\mathbf{2 0 1 5}$ & $\mathbf{2 0 1 5}$ & $\mathbf{2 0 1 5}$ & $\mathbf{2 0 1 5}$ & $\mathbf{2 0 1 5}$ & $\mathbf{2 0 1 6}$ & $\mathbf{2 0 1 6}$ & $\mathbf{2 0 1 6}$ & $\mathbf{2 0 1 6}$ & $\mathbf{2 0 1 6}$ & Matter & \\
\hline LigriXFaara/1 & 4.00 & 3.00 & 1.80 & 0.25 & 13.66 & 3.00 & 3.00 & 0.90 & 0.09 & 6.57 & 45.84 & 32.83 \\
LigriXFaara/2 & 4.00 & 2.00 & 2.05 & 0.15 & 14.67 & 3.50 & 1.50 & 0.85 & 0.05 & 5.97 & 44.80 & 31.45 \\
LigriXFaara/3 & 5.00 & 0.50 & 2.40 & 0.01 & 16.02 & 2.00 & 0.50 & 0.53 & 0.04 & 3.76 & 47.84 & 33.08 \\
LigriXFaara/4 & 3.00 & 1.00 & 1.00 & 0.05 & 7.00 & 4.00 & 2.00 & 1.25 & 0.10 & 9.00 & 48.11 & 32.65 \\
LigriXFaara/5 & 3.50 & 2.50 & 1.10 & 0.20 & 8.66 & 4.50 & 3.00 & 0.55 & 0.09 & 4.23 & 47.11 & 30.77 \\
LigriXFaara/6 & 4.50 & 1.50 & 1.45 & 0.10 & 10.33 & 2.50 & 5.00 & 0.65 & 0.20 & 5.63 & 49.24 & 33.14 \\
LigriXFaara/7 & 5.00 & 0.00 & 1.15 & 0.00 & 7.67 & 2.00 & 3.00 & 0.50 & 0.08 & 3.83 & 45.97 & 29.45 \\
LigriXFaara/8 & 2.50 & 1.50 & 0.45 & 0.10 & 3.66 & 3.00 & 1.50 & 0.75 & 0.10 & 5.36 & 51.50 & 32.14 \\
LigriXFaara/9 & 3.50 & 1.50 & 0.75 & 0.10 & 5.66 & 3.00 & 2.00 & 0.75 & 0.05 & 5.33 & 50.31 & 30.45 \\
LigriXFaara/10 & 4.00 & 2.00 & 0.95 & 0.15 & 7.33 & 2.00 & 2.50 & 0.30 & 0.10 & 2.67 & 39.73 & 27.13 \\
LigriXFaara/11 & 4.00 & 1.00 & 0.85 & 0.05 & 6.00 & 2.50 & 3.50 & 0.75 & 0.10 & 5.65 & 49.00 & 26.30 \\
LigriXFaara/12 & 2.50 & 0.50 & 0.70 & 0.05 & 5.00 & 2.50 & 1.50 & 0.83 & 0.05 & 5.80 & 48.87 & 31.27 \\
LigriXFaara/13 & 3.50 & 0.00 & 0.85 & 0.00 & 5.66 & 3.50 & 0.00 & 0.85 & 0.00 & 5.66 & 49.44 & 27.51 \\
LigriXFaara/14 & 3.00 & 1.00 & 0.40 & 0.10 & 3.33 & 3.00 & 1.00 & 0.40 & 0.10 & 3.33 & 49.69 & 23.31 \\
LigriXFaara/15 & 3.00 & 2.00 & 1.10 & 0.10 & 8.00 & 3.00 & 2.00 & 1.10 & 0.10 & 8.00 & 47.43 & 30.33 \\
LigriXFaara/16 & 4.00 & 2.00 & 0.95 & 0.15 & 7.33 & 3.00 & 3.00 & 0.55 & 0.09 & 4.23 & 50.21 & 29.85 \\
LigriXFaara/17 & 4.00 & 1.00 & 0.85 & 0.05 & 6.00 & 3.00 & 2.50 & 0.95 & 0.10 & 6.97 & 50.12 & 26.91 \\
SautiXBohye/1 & 5.50 & 0.00 & 2.30 & 0.00 & 15.30 & 3.00 & 1.00 & 1.10 & 0.10 & 8.00 & 45.35 & 21.76 \\
\hline
\end{tabular}


Vol. 06, No. 06; 2021

ISSN: $2456-8643$

\begin{tabular}{|c|c|c|c|c|c|c|c|c|c|c|c|c|}
\hline SautiXBohye/2 & 4.50 & 2.00 & 2.75 & 0.15 & 19.33 & 4.00 & 0.00 & 0.90 & 0.00 & 6.00 & 44.72 & 25.34 \\
\hline SautiXBohye/3 & 4.00 & 2.00 & 2.25 & 0.15 & 16.00 & 2.00 & 1.00 & 0.50 & 0.08 & 3.86 & 37.37 & 25.78 \\
\hline SautiXBohye/4 & 4.00 & 1.50 & 1.95 & 0.11 & 13.65 & 2.50 & 2.00 & 0.48 & 0.10 & 3.80 & 45.67 & 22.32 \\
\hline SautiXBohye/5 & 3.00 & 0.50 & 1.35 & 0.05 & 9.32 & 3.00 & 1.00 & 0.75 & 0.05 & 5.33 & 43.51 & 21.58 \\
\hline SautiXBohye/6 & 4.50 & 1.00 & 2.30 & 0.10 & 15.98 & 2.00 & 1.00 & 0.50 & 0.15 & 4.33 & 44.18 & 26.76 \\
\hline SautiXBohye/7 & 3.00 & 1.50 & 1.28 & 0.00 & 8.47 & 1.00 & 2.00 & 0.40 & 0.05 & 3.00 & 43.97 & 24.10 \\
\hline SautiXBohye/8 & 2.00 & 4.00 & 0.50 & 0.20 & 4.66 & 4.00 & 2.00 & 1.20 & 0.10 & 8.06 & 45.87 & 24.23 \\
\hline SautiXBohye/9 & 2.00 & 0.00 & 0.80 & 0.00 & 5.33 & 3.00 & 4.00 & 1.10 & 0.10 & 8.00 & 44.00 & 20.76 \\
\hline SautiXBohye/10 & 2.00 & 0.00 & 0.55 & 0.00 & 3.66 & 1.00 & 4.00 & 0.20 & 0.10 & 2.00 & 44.56 & 25.40 \\
\hline SautiXBohye/11 & 3.00 & 2.00 & 0.50 & 0.10 & 4.00 & 2.00 & 5.00 & 0.40 & 0.10 & 3.30 & 46.50 & 25.82 \\
\hline SautiXBohye/12 & 6.00 & 1.00 & 0.40 & 0.10 & 3.33 & 2.00 & 3.00 & 0.55 & 0.09 & 4.26 & 43.29 & 22.42 \\
\hline SautiXBohye/13 & 2.00 & 7.00 & 0.50 & 0.30 & 5.33 & 3.00 & 0.00 & 0.40 & 0.00 & 2.66 & 44.44 & 21.61 \\
\hline SautiXBohye/14 & 3.00 & 4.00 & 0.60 & 0.10 & 4.66 & 3.00 & 1.00 & 0.40 & 0.10 & 3.33 & 44.74 & 26.74 \\
\hline SautiXBohye/15 & 1.00 & 0.00 & 0.20 & 0.00 & 1.33 & 3.00 & 2.00 & 1.10 & 0.10 & 8.00 & 40.53 & 24.23 \\
\hline SautiXBohye/16 & 2.00 & 0.00 & 0.55 & 0.00 & 3.66 & 2.00 & 0.00 & 0.55 & 0.00 & 3.66 & 45.62 & 24.10 \\
\hline SautiXBohye/17 & 3.00 & 2.00 & 0.50 & 0.10 & 4.00 & 3.00 & 2.00 & 0.50 & 0.10 & 4.00 & 43.66 & 20.89 \\
\hline SautiX442162/1 & 4.50 & 3.50 & 3.35 & 2.55 & 8.20 & 2.00 & 4.50 & 0.45 & 0.08 & 3.45 & 19.45 & 80.11 \\
\hline SautiX442162/2 & 3.50 & 4.50 & 1.60 & 0.20 & 11.40 & 2.50 & 4.00 & 0.63 & 0.08 & 4.70 & 33.43 & 66.14 \\
\hline SautiX442162/3 & 2.50 & 1.50 & 0.60 & 0.13 & 4.83 & 3.00 & 4.00 & 0.75 & 0.08 & 5.53 & 22.49 & 77.51 \\
\hline SautiX442162/4 & 2.00 & 1.00 & 0.50 & 0.03 & 3.50 & 2.00 & 2.50 & 0.60 & 0.07 & 4.47 & 42.41 & 57.19 \\
\hline SautiX442162/5 & 6.00 & 1.00 & 1.80 & 0.05 & 12.03 & 3.00 & 3.00 & 0.85 & 0.08 & 5.83 & 44.01 & 55.99 \\
\hline SautiX442162/6 & 2.00 & 2.50 & 0.15 & 0.06 & 1.37 & 2.00 & 2.50 & 0.15 & 0.06 & 1.37 & 42.32 & 57.36 \\
\hline Umuspo 3 & 3.00 & 0.00 & 1.10 & 0.00 & 7.33 & 3.00 & 2.50 & 0.65 & 0.05 & 8.06 & 42.98 & 27.22 \\
\hline TIS 87/0087 & 4.00 & 0.00 & 1.30 & 0.00 & 8.66 & 3.50 & 3.50 & 0.60 & 0.05 & 8.33 & 39.24 & 23.73 \\
\hline Grand mean & 3.45 & 1.56 & 1.15 & 0.14 & 7.89 & 2.73 & 2.26 & 0.67 & 0.08 & 5.13 & 44.03 & 32.32 \\
\hline $\operatorname{LSD}_{0.05}$ & 1.31 & 1.82 & 1.1 & NS & 6.69 & 1.08 & 1.94 & NS & 0.05 & 2.74 & 2.17 & 3.14 \\
\hline
\end{tabular}

MRN $=$ Marketable root number, $\mathrm{URN}=$ Unmarketable root number, MRW $=$ Marketable root weight, URW $=$ Unmarketable root weight

Table 3 showed the Pearson correlation co-efficients $(\gamma)$ for the storage root parameters for forty genotypes. Total storage root yield had significant and positive correlation coefficient with number of marketable roots and marketable weight/ha but negative correlation coefficient with number of unmarketable roots (Table 3). Correlation coefficients for the 7 traits are presented in Table 3. Generally, all the traits except unmarketable storage root weight at harvest exhibited positive and significant $(\mathrm{P} \leq 0.05$ and $\mathrm{P} \leq 0.01)$ correlation with total roots weight (yield). Some of the traits also exhibited significant and positive association among themselves as well as significant and negative association. Yield at harvest had a positive association with unmarketable fresh storage root number $(r=0.08)$ (Table 3). Yield at harvest, however, had a negative association with unmarketable fresh storage root weight $(r=-0.02)$. Yield at harvest had a negative association with dry matter $(r=-0.036)$ and starch $(r=-0.034)$ (Table 3$)$ 
Table 3: Pearson correlation co-efficients $(\gamma)$ for the storage root parameters for the 40 genotypes of sweetpotato

\begin{tabular}{|c|c|c|c|c|c|c|c|}
\hline & MRN & URN & MRW & URW & Yield & Dry matter & Starch \\
\hline \multicolumn{8}{|l|}{ MRTN } \\
\hline UMRTN & -0.087 & & & & & & \\
\hline MRTW & $0.603^{* *}$ & 0.108 & & & & & \\
\hline UMRTW & 0.122 & $0.363^{* *}$ & $0.458^{* *}$ & & & & \\
\hline Yield & $0.591^{* *}$ & 0.083 & $0.857^{* *}$ & -0.028 & & & \\
\hline Dry matter & 0.015 & -0.191 & $-0.245^{*}$ & $-0.427^{* *}$ & -0.036 & & \\
\hline Starch & 0.035 & 0.201 & 0.154 & $0.365^{* * *}$ & -0.034 & $-0.675^{* *}$ & \\
\hline \multicolumn{8}{|c|}{$\begin{array}{l}\text { **. Correlation is significant at the } 0.01 \text { level (2-tailed). } \\
* \text {. Correlation is significant at the } 0.05 \text { level (2-tailed). }\end{array}$} \\
\hline
\end{tabular}

\subsection{Principal component analyses}

Two principal component axes (PC1 and $\mathrm{PC} 2$ ) in the principal component analysis ( $\mathrm{PC}$ analysis had eigen values up to 1.0 , presenting cumulative variance of $65.89 \%$ (Table 4). Principal component one ( $\mathrm{PC} 1)$, with eigen value of 2.64 , contributed $37.57 \%$ of the total variability, while PC2, with eigen value of 1.96 , accounted for $28.13 \%$ of total variability observed among the 40 sweetpotato genotypes. In PC1, the traits that accounted for most of the $37.57 \%$ observed variability among the 40 genotypes included number of marketable roots, with vector loading of 0.616 , unmarketable storage root number (0.314), weight of marketable roots $(0.902)$, weight of unmarketable roots $(0.598)$, yield $(0.700)$, dry matter and starch contents $(-0.530$ and 0.472 , respectively) (Table 4).

Table 4: Principal component analysis of the 141 sweetpotato genotypes

\begin{tabular}{|lll|}
\hline & PCA 1 & PCA 2 \\
\hline MRN & 0.616 & 0.536 \\
URN & 0.314 & -0.396 \\
\hline
\end{tabular}




\begin{tabular}{|lcc|}
\hline MRW & 0.902 & 0.333 \\
URW & 0.598 & -0.468 \\
Yield & 0.700 & 0.600 \\
Dry matter & -0.530 & 0.640 \\
Starch & 0.472 & -0.652 \\
Total & 2.643 & 1.969 \\
\% of Variance & 37.757 & 28.136 \\
Cumulative \% & 37.757 & 65.892 \\
\hline
\end{tabular}

RN = Marketable root number, URN = Unmarketable root number, MRW = Marketable root weight, URW = Unmarketable root weight

The current result agrees with the findings of Andrade et al. (2009), who reported that the total storage root yields of five sweetpotato varieties from Sub-Saharan Africa ranged between 0.5 and 65t/ha. Consistent with the results of this study, Mcharo and Ndolo (2013) and Nedunchezhiyan et al. (2007) reported large differences between sweetpotato clones in terms of root yield due to genetic variation. Similarly, Yanggen and Nagujja, (2006) reported that population averages across varieties, locations and replications for storage root yield were low at $8.6 \mathrm{t} / \mathrm{ha}$, but above the national average of $4.2 \mathrm{t} / \mathrm{ha}$ in Uganda. Consistent with the results of this study, Wassu et al. (2015) reported significant variations between 116 sweetpotato genotypes that included the genotypes tested in this experiment, with a mean total fresh root yield from storage of 10.74 (t/ha) and a range of 2.26 to $28.46 \mathrm{t} / \mathrm{ha}$. The high yielding genotypes could be incorporated into sweetpotato breeding programs to improve the yield of other accessions. According to Afuape et al. (2011), within the group of genotypes, PCA is a technique to identify which plant traits is the most contributing to the observed variation. Afuape et al. (2011), who reported a cumulative variance of $76.00 \%$ for the first three axes in the evaluation of twenty-one sweetpotato genotypes, found important traits to be the genotypes they worked with. Four main principal components (PC) were identified, accounting for $67.22 \%$ of the total variation between accessions (Koussao et al., 2014). Placide et al., (2015) also used PCA to study the variability between 54 sweetpotato genotypes and found the cumulative variance of $77.83 \%$ from the first seven major component axes. The results of this study are in agreement with the results of these authors as there was enough variability to support the choice between genotypes.

\section{CONCLUSION}

Analysis of variance showed the significant difference among the forty tested genotypes in all traits observed. The descriptive analysis showed that root yield ranged from 2.2- 19.33t/ha with an average $7.86 \mathrm{t} / \mathrm{ha}$ and starch content ranged from $80.11 \mathrm{mg} 100 \mathrm{~g}^{-1}$ to $20.76 \mathrm{mg} 100^{-1}$. SautiX442162/1 had the highest starch content, $80.11 \mathrm{mg} 100 \mathrm{~g}^{-1}$ while SautiXBohye/9 had the 
Vol. 06, No. 06; 2021

ISSN: $2456-8643$

lowest starch content, $20.76 \mathrm{mg} 100^{-1}$. The mean of the genotypes for dry matter ranged from $51.50 \%$ to $19.45 \%$ with an average $44.03 \%$. The study showed that thirteen genotypes produced higher fresh storage root yield than the national check (TIS 87/0087). Five promising genotypes; LigriXFaara/2 (14.67t/ha), LigriXFaara/3 (16.02t/ha), SautiXBohye/1 (15.03t/ha), SautiXBohye/2 (19.33t/ha), SautiXBohye/3 (16.00t/ha recorded high yield above the world's estimated annual average yield of $13.7 \mathrm{t} / \mathrm{ha}$. Six promising genotypes recorded starch content above $50.00 \mathrm{mg} 100^{-1} ; \quad$ SautiX442162/1 $\quad\left(80.11 \mathrm{mg}_{100^{-1}}\right)$, SautiX442162/3 $\quad\left(77.51 \mathrm{mg} 100^{-1}\right)$, SautiX442162/2 (66.14mg $\left.100^{-1}\right)$, SautiX442162/6 (57.36 mg100-1), SautiX442162/4 (57.19 $\left.\mathrm{mg} 100^{-1}\right)$, SautiX442162/5 $\left(55.99 \mathrm{mg} 100^{-1}\right)$. The low yield recorded in 2016 planting season could be attributed to early planting in the month of April. Eleven promising genotypes that recorded high yield and starch could be subjected to multi-location trail and incorporated into further breeding program.

\section{ACKNOWLEDGMENT}

The first author thanks Prof. Peter I. O. for providing thorough supervision through this study. The first author also thanks Dr Afuape S. O. (the second author) for sourcing the plant materials and support during this research. Mr. Ulasi Eugene and Mrs. Ulasi Patricia are thanked immensely for their financial support during this research.

\section{REFERENCES}

Afuape SO, Okocha PI, Njoku D. 2011. Multivariate assessment of the agromorphological variability and yield components among sweetpotato (Ipomoea batatas (L.) Lam) landraces. Afr J Pl Sci 5 (2): 123-132.

Andrade, E.K.V., V. Carvalho de Andrade Junior, M. Luiz de Laia, J.S. Cunha Fernandes, A.J.M. Oliveira, and A.M. Azevedo. 2017. Genetic dissimilarity among sweetpotato genotypes using morphological and molecular descriptors. Acta Sci. Agron. 39:447-455.

Daros, M., A.T. Amaral, Jr., T.N.S. Pereira, N.R. Leal, S.P. Freitas, and T. Sediyama. 2002. Caracterizacx ao morfologica de acessos de batata-doce [Morphologic characterization of sweetpotato]. Hort. Bras. 20:43-47.

FAOSTAT, 2009. Global Production and Consumption of Root and Tuber. In FAO Corporate Document Repository. Report on the Inter-Center Review of Root and Tuber Crops Research in the CGIAR. http://www.fao.org. Accessed in June15 2009

Koussao, S., V. Gracen, I. Asante, E.Y. Danquah, J.T. Ouedraogo, T.J. Baptiste, and T.M. Vianney. 2014. Diversity analysis of sweetpotato [Ipomoea batatas (L.) Lam] germplasm from Burkina Faso using morphological and simple sequence repeats markers. Afr. J. Biotechnol. 13:729-742.

Levett, M. P. (1993). The effects of methods of planting cuttings of sweetpotato (Ipomoea batatas (L) Lam) on yield. Tropical Agriculture (Trinidad), 70(2), 110-115.

Loebenstein G. (2009). Origin, Distribution and Economic Importance. In: Loebenstein G., Thottappilly G. (eds) The Sweetpotato. Springer, Dordrecht. https://doi.org/10.1007/978-1-40209475-0_21986 
Vol. 06, No. 06; 2021

ISSN: $2456-8643$

Mcharo and Ndolo. 2013. Sweetpotato root-yield performance in Kenya 4914 Root-yield performance of pre-release sweetpotato genotypes in Kenya. Journal of Applied Biosciences. 65:4914 - 4921: ISSN 1997-5902.

Mwanga, R., Yencho, G. and Moyer, J. (2002). Diallel analysis of sweetpotatoes for resistance to sweetpotato virus disease. Euphytica 128: 237-248.

National Root Crops Research Institute (2012). Annual Report of the National Root Crops Research Institute, Umudike.

Odebode SD (2004). Acceptability of sweetpotato "sparri" and its potentials for enhancing food security and economic empowerment of rural woman in Southeastern Nigeria. Nig. J. Rural Sociol. 1(2):104-112

Placide, R., H. Shimelis, M. Laing, and D. Gahakwa. 2015. Phenotypic characterisation of sweetpotato genotypes grown in East and Central Africa. S. Afr. J. Plant Soil 32:77-86

Rahman, S. M. M.; Wheatley, C. ; Rakshit, S. K., 2003. Selection of sweetpotato variety for high starch extraction. Int. J. Food Propert., 6 (3): 419-430

Singh, S., C. S. Riar and D. C. Saxena (2008). Effect of incorporating sweetpotato flour to wheat flour on the quliaty characteristics of cookies. Agri. J. Food Sci. 2:065-072.

Tewe, O. O., Ojeniyi, F. E. and Abu, O. A. (2003). Sweetpotato production, utilization and marketing in Nigeria. Social Sciences Department, International Potato Centre, Lima, Peru. Accessed October 2010. Available at http://www.eseap.cipotato-org/MFESEAP/F/-Library/Spin Nigeria pdf.

Thottappilly, G. and G. Loebenstein. (2009). Introductory remarks. In The Sweetpotato. G. Thottappilly and G. Loebenstein (eds). Springer Science+ Business Media B. V. 2009. Springer, New York.

Wang. S. S., Chiang, W. C, Yeh, A. 1. Zhao. B., and Kim, I. H. (1989). Kinetics of phase transition of waxy com starch at extrusion temperatures and moisture contents. J. Food Sci. 54: 1298-130 I

Wassu Mohammed, Solomon Ali, Beneberu Shimelis and Simret Burga (2015). Genetic Diversity of Local and Introduced Sweetpotato [Ipomoea batatas (L.) Lam.] Collections for Agro-morphology and Physicochemical Attributes in Ethiopia. Science, Technology and Arts Research Journal 4(1): 09-19.

Willcox DC, Willcox BJ, Todoriki H, Suzuki M. (2009).The Okinawan diet: health implications of a low-calorie, nutrient-dense, antioxidant-rich dietary pattern low in glycemic load. J. Am. Coll. Nutr.28(Suppl):500S-516S.

Yanggen, D., and Nagujja, S. (2006). The use of orange fleshed sweetpotato to combat vitamin A deficiency in Uganda. Study of varietal preferences, extension strategies and post harvest utilization (International Potato Center (CIP) Lima, Peru). 